\title{
Early mitral valve surgery for chronic severe mitral regurgitation optimizes left ventricular performance and left ventricular mass regression
}

\author{
Ken-ichi Imasaka, MD, PhD, ${ }^{a}$ Yukihiro Tomita, $\mathrm{MD}, \mathrm{PhD},{ }^{\mathrm{a}}$ Yoshihisa Tanoue, $\mathrm{MD}, \mathrm{PhD},{ }^{\mathrm{b}}$ \\ Ryuji Tominaga, MD, PhD, ${ }^{b}$ Eiki Tayama, $\mathrm{MD}, \mathrm{PhD},{ }^{\mathrm{a}}$ Hirofumi Onitsuka, MD, ${ }^{\mathrm{a}}$ and Tomohiro Ueda, $\mathrm{MD}^{\mathrm{a}}$
}

Objective: The optimal timing of mitral valve surgery for severe mitral regurgitation is controversial. We aimed to evaluate the changes in left ventricular performance using ventricular energetics and left ventricular mass regression after the surgery to determine the appropriate surgical timing in asymptomatic patients with severe mitral regurgitation.

\begin{abstract}
Methods: Fifty consecutive asymptomatic or minimally symptomatic patients who electively underwent the surgery for severe mitral regurgitation were studied retrospectively. Contractility (end-systolic elastance), afterload (effective arterial elastance), and efficiency (ventriculoarterial coupling and ratio of stroke work to pressure-volume area), and left ventricular mass index were measured echocardiographically before and 1 month after surgery. Two-way repeated-measures analysis of variance was used to compare the parameters between patients with $(\mathrm{n}=17)$ and without $(\mathrm{n}=33)$ left ventricular dysfunction (ie, ejection fraction $\leq 60 \%$ and/or end-systolic dimension $\geq 40 \mathrm{~mm}$ ).
\end{abstract}

Results: Contractility did not change significantly $(P=.94)$ but the afterload increased significantly $(P<.0001)$ in both groups. Consequently, the efficiency deteriorated significantly (ventriculoarterial coupling, $P=.0004$; ratio of stroke work to pressure-volume area, $P<.0001$ ). Furthermore, the left ventricular mass index improved remarkably in both groups $(P<.0001)$. Alternatively, the patients with normal left ventricular function had greater contractility $(P<.0001)$, less worsened efficiency $(P<.0001$ and $P<.0001$, respectively), and a better left ventricular mass index $(P=.0002)$ after surgery.

Conclusions: Early surgery for severe mitral regurgitation preserves left ventricular performance and improves left ventricular mass regression in asymptomatic patients with normal ventricular function. (J Thorac Cardiovasc Surg 2013;146:61-6)

Degenerative mitral regurgitation (MR) is the most frequent cause of organic mitral valve (MV) disease in Western countries and is often discovered accidentally in asymptomatic patients. ${ }^{1}$

The optimal timing of MV surgery for MR remains controversial, because patients with chronic MR can be asymptomatic for a long period. In particular, the role of early surgery has been debated. ${ }^{2,3}$ Rosenhek and colleagues ${ }^{2}$ reported good outcomes with a watchful strategy in which 132 asymptomatic patients with severe MR were followed up for $62 \pm 26$ months by echocardiographic and clinical

\footnotetext{
From the Department of Cardiovascular Surgery, ${ }^{a}$ Clinical Research Institute, National Hospital Organization Kyushu Medical Center, Fukuoka, Japan; and Department of Cardiovascular Surgery, ${ }^{\text {b }}$ Kyushu University, Fukuoka, Japan. Disclosures: Authors have nothing to disclose with regard to commercial support. Presented in part at the Scientific Sessions 2011 of the American Heart Association, Orlando, Florida, November 12-16, 2011.

Received for publication Feb 3, 2012; revisions received April 9, 2012; accepted for publication May 16, 2012; available ahead of print June 20, 2012.

Address for reprints: Yukihiro Tomita, MD, PhD, Department of Cardiovascular Surgery, National Hospital Organization Kyushu Medical Center, 1-8-1 Jigyo-hama, Chuo-ku, Fukuoka 812-8582, Japan (E-mail: ytomita@kyumed.jp). 0022-5223/ $\$ 36.00$

Copyright (c) 2013 by The American Association for Thoracic Surgery doi:10.1016/j.jtcvs.2012.05.056
}

examinations. In contrast, the American College of Cardiology/American Heart Association guidelines recommend early surgery for asymptomatic patients with severe MR and a high probability of MV repair. ${ }^{3}$

Furthermore, although MV surgery for MR is followed by left ventricular (LV) adjustment to the new preload and afterload, ${ }^{4,5}$ little has been reported on the postoperative LV mechanics and LV reverse remodeling.

End-systolic elastance (Ees), effective arterial elastance (Ea), and ventriculoarterial coupling (Ea/Ees), and the stroke work to pressure-volume area (SW/PVA) ratio enable analysis of LV contractility, afterload, and efficiency, respectively. ${ }^{6,7}$ These parameters have been validated and used in previous basic and clinical studies of LV performance. ${ }^{8-15}$

An increased LV mass index (LVMI) is reportedly an independent factor for the development of symptoms in asymptomatic patients with severe aortic stenosis. ${ }^{16}$ Moreover, incomplete LVM regression after MV surgery for MR has been correlated with decreased LV function and the degree of preoperative tricuspid valve regurgitation. ${ }^{17}$

The assessment of the postoperative LV performance and LVM regression in asymptomatic patients should help 


$$
\begin{aligned}
& \text { Abbreviations and Acronyms } \\
& \begin{aligned}
\mathrm{Ea} & =\text { effective arterial elastance } \\
\mathrm{Ees} & =\text { end-systolic elastance } \\
\mathrm{Ea} / \mathrm{Ees} & =\text { ventriculoarterial coupling } \\
\mathrm{EF} & =\text { ejection fraction } \\
\mathrm{LV} & =\text { left ventricular } \\
\mathrm{LVEDVI} & =\mathrm{LV} \text { end-diastolic volume index } \\
\mathrm{LVESVI} & =\mathrm{LV} \text { end-systolic volume index } \\
\mathrm{LVM} & =\mathrm{LV} \text { mass } \\
\mathrm{LVMI} & =\mathrm{LV} \text { mass index } \\
\mathrm{MR} & =\text { mitral regurgitation } \\
\mathrm{MV} & =\text { mitral valve } \\
\mathrm{SW} / \mathrm{PVA} & =\text { stroke work/pressure-volume area } \\
& \text { (ratio) }
\end{aligned}
\end{aligned}
$$

elucidate the optimal timing of MV surgery for MR. Therefore, we evaluated the changes in LV performance and LVM regression after MV surgery on the basis of LV mechanics and LVMI, respectively, in asymptomatic patients with chronic severe MR.

\section{METHODS}

\section{Study Population}

A total of 50 consecutive asymptomatic or minimally symptomatic patients who electively underwent MV surgery for chronic severe MR from January 1, 2007 to September 30, 2010 at Kyushu Medical Center were retrospectively studied. All patients had degenerative or myxomatous valve disease, and 4 patients had a remote history of endocarditis.

The inclusion criteria were (1) preoperative New York Heart Association class I or II; and (2) MR due to degenerative or myxomatous MV disease, even in the case of a remote history of endocarditis. The patients who underwent tricuspid annuloplasty, the maze procedure, or closure of atrial septal defects were not excluded. The exclusion criteria were (1) preoperative New York Heart Association class III or IV; (2) associated mitral stenosis; (3) associated aortic or tricuspid valve replacement or coronary artery bypass grafting; (4) ischemic MR, cardiomyopathy, rheumatic valve disease, or acute endocarditis; (5) LV ejection fraction (EF) $\leq 0.30$; and (6) previous valve surgery.

\section{Surgical Procedures}

The MV surgery was performed under cardiopulmonary bypass, with aortic and bicaval cannulation and moderate hypothermia. Myocardial protection was achieved using antegrade and retrograde cardioplegia. MV repair $(\mathrm{n}=36)$ was performed singly or in combination with the following techniques: artificial chordal reconstruction in 17, quadrangular or triangular resection in 18, commissuroplasty in 11, and an edge-to-edge technique in 13. Ring annuloplasty was performed in all the MV repair cases. The posterior leaflet and chords were preserved in the MV replacement cases $(\mathrm{n}=14)$. Finally, 6 and 8 patients received mechanical valves and biologic prostheses, respectively.

\section{Echocardiographic Data}

The MR severity was assessed by transesophageal or transthoracic echocardiography before and approximately 1 month after the surgery. It was graded according to the published guidelines using an integrated approach that included valvular morphologic characteristics, regurgitant jet size in the left atrium, proximal regurgitant jet width, and pulmonary venous flow pattern. ${ }^{18}$

LV mechanics. The blood pressure (BP) was measured using the Korotkoff technique and the manchette method. The mean arterial BP was calculated as follows:

$$
\text { Mean arterial BP }=(\text { systolic } \mathrm{BP}-\text { diastolic BP }) / 3+\text { diastolic BP }
$$

The LV volume was calculated using the Teichholz M-mode method based on the transthoracic echocardiographic data. ${ }^{19}$ The LV enddiastolic volume index (LVEDVI) and LV end-systolic volume index (LVESVI) were calculated. Next, the EF (\%) was calculated as follows:

$$
\mathrm{EF}=(1-\mathrm{LVESV} / \mathrm{LVEDV}) \times 100
$$

The Ees, Ea, and Ea/Ees were calculated using an approximation method on the basis of the arterial BP and volumetric data obtained by transthoracic echocardiography. ${ }^{8-14}$ The approximation of Ees and Ea was as follows:

$$
\begin{gathered}
\text { Ees }=\text { mean arterial BP/LVESV } \\
\text { Ea }=\text { systolic BP } /(\text { LVEDV }- \text { LVESV })
\end{gathered}
$$

The LV volume was normalized by the body surface area. Ea/Ees ${ }^{7}$ and SW/PVA were calculated as indexes of LV efficiency. The SW/PVA (\%) was calculated as follows ${ }^{20}$ :

$$
\mathrm{SW} / \mathrm{PVA}=1 /(1+0.5 \mathrm{Ea} / \text { Ees }) \times 100
$$

LVM index. The LVM (g) was calculated as follows ${ }^{21}$ :

$$
\begin{array}{r}
\mathrm{LVM}=0.80(1.04[\text { LVEDD }+ \text { posterior wall thickness in diastole } \\
\left.+ \text { septal wall thickness in diatole }]^{3}-\text { LVEDD }^{3}\right)+0.6
\end{array}
$$

where LVEDD is the LV end-diastolic dimension. The obtained result was indexed for body surface area in grams per square meter.

\section{Statistical Analysis}

For analysis, the patients were grouped as follows: group A, patients with LV dysfunction (LVEF $\leq 60 \%$ and/or LV end-systolic dimension [LVESD] $\geq 40 \mathrm{~mm}$ ); and group B, patients without LV dysfunction (LVEF $>60 \%$ and LVESD $<40 \mathrm{~mm}$ ).

The data are presented as the mean \pm standard deviation. Categorical variables were compared using the unpaired $t$ test and chi-square test. Two-way repeated measures analysis of variance was used to compare the LV parameters before and after surgery. It was used to clarify whether the repeated (measurement points) and nonrepeated (groups) factors were significantly different among the levels and whether the interactions between these factors were significant. The analysis was also used to determine whether the variables were significantly different between the measurement points or between the patients groups. The StudentNewman-Keuls test was used as a post hoc test. A $P$ value less than .05 was considered to be statistically significant.

\section{RESULTS}

\section{Patient Characteristics}

Perioperative and in-hospital deaths did not occur. The patients in group A had a larger left atrium $(P=.006)$, LVEDD $(P<.0001)$, and LVESD $(P<.0001)$ and lower LVEF $(P<.0001)$ than the patients in group B (Table 1$).$ Moreover, they had a greater rate of atrial fibrillation or 
TABLE 1. Baseline characteristics

\begin{tabular}{|c|c|c|c|c|}
\hline Parameter & $\begin{array}{c}\text { Total } \\
(\mathbf{n}=\mathbf{5 0})\end{array}$ & $\begin{array}{l}\text { Group A } \\
(\mathbf{n}=17)\end{array}$ & $\begin{array}{l}\text { Group B } \\
(\mathbf{n}=\mathbf{3 3})\end{array}$ & $\begin{array}{l}P \text { value } \\
(A \text { vs } B)\end{array}$ \\
\hline Age (y) & $63.9 \pm 12.6$ & $62.8 \pm 9.5$ & $64.5 \pm 14.1$ & .64 \\
\hline Male & $35(70)$ & $12(71)$ & $23(70)$ & .95 \\
\hline $\operatorname{BSA}\left(\mathrm{m}^{2}\right)$ & $1.6 \pm 0.2$ & $1.7 \pm 0.2$ & $1.6 \pm 0.2$ & .14 \\
\hline Smoking & $22(44)$ & $8(47)$ & $14(42)$ & .76 \\
\hline Diabetes & $8(16)$ & $3(18)$ & $5(15)$ & .82 \\
\hline Hypertension & $27(54)$ & $11(65)$ & $16(48)$ & .28 \\
\hline $\begin{array}{l}\text { Total cholesterol } \\
\quad(\mathrm{mg} / \mathrm{dL})\end{array}$ & $179 \pm 38$ & $185 \pm 42$ & $176 \pm 37$ & .44 \\
\hline $\begin{array}{l}\text { Serum creatinine } \\
\quad(\mathrm{mg} / \mathrm{dL})\end{array}$ & $0.9 \pm 0.2$ & $0.9 \pm 0.3$ & $0.9 \pm 0.2$ & .87 \\
\hline ACEI or ARB & $33(66)$ & $14(82)$ & $19(58)$ & .08 \\
\hline$\beta$-blocker & $18(36)$ & $8(47)$ & $10(30)$ & .24 \\
\hline Diuretic & $40(80)$ & $16(94)$ & $24(73)$ & .07 \\
\hline Warfarin & $24(48)$ & $11(65)$ & $13(39)$ & .09 \\
\hline Antiplatelet agent & $11(22)$ & $5(29)$ & $6(18)$ & .37 \\
\hline Af or $\mathrm{AF}$ & $17(34)$ & $9(53)$ & $8(24)$ & .04 \\
\hline $\begin{array}{l}\text { Systolic PAP } \\
(\mathrm{mm} \mathrm{Hg})\end{array}$ & $40.1 \pm 14.0$ & $46.8 \pm 17.2$ & $36.1 \pm 10.2$ & .01 \\
\hline LA size $(\mathrm{mm})$ & $50.5 \pm 12.7$ & $57.2 \pm 12.0$ & $47.1 \pm 11.8$ & .006 \\
\hline LVEDD (mm) & $57.9 \pm 7.6$ & $64.6 \pm 1.5$ & $54.5 \pm 1.0$ & $<.0001$ \\
\hline LVESD (mm) & $34.7 \pm 1.0$ & $43.3 \pm 3.0$ & $30.3 \pm 3.5$ & $<.0001$ \\
\hline $\operatorname{LVEF}(\%)$ & $64.5 \pm 10.5$ & $54.7 \pm 10.7$ & $69.5 \pm 5.9$ & $<.0001$ \\
\hline $\mathrm{TR}$ & & & & .06 \\
\hline Absent & $11(22)$ & $1(6)$ & $10(30)$ & \\
\hline Trivial to mild & $29(58)$ & $10(59)$ & $19(58)$ & \\
\hline Moderate & $7(14)$ & $5(29)$ & $2(6)$ & \\
\hline Severe & $3(6)$ & $1(6)$ & $2(6)$ & \\
\hline
\end{tabular}

Data presented as the mean \pm standard deviation or number (percentages). Group A, patients with LV dysfunction; group $\mathrm{B}$, patients without $\mathrm{LV}$ dysfunction. $B S A$, Body surface area; $A C E I$, angiotensin-converting enzyme inhibitor; $A R B$, angiotensin receptor blocker; $A f$, atrial fibrillation; $A F$, atrial flutter; $P A P$, pulmonary artery pressure; $L A$, left atrium; $L V E D D$, left ventricular end-diastolic dimension; $L V E S D$, left ventricular end-systolic dimension; $L V E F$, left ventricular ejection fraction; $T R$, tricuspid regurgitation.

flutter $(P=.04)$ and greater systolic pulmonary artery BP $(P=.01)$. Tricuspid annuloplasty was performed more frequently in group A than in group B $(P=.03)$. However, the cardiopulmonary bypass and aortic cross-clamping times were not significantly different (Table 2). Echocardiograms at 1 month after MV repair revealed no MR in 15 patients and trivial regurgitation in 21 patients. No patient who underwent MV replacement had paravalvular leaks. The mean gradient across the MV was $2.9 \pm 1.1$ and $3.6 \pm 0.8 \mathrm{~mm} \mathrm{Hg}$ at 1 month after MV repair and MV replacement, respectively.

\section{Volume and Parameters}

As shown in Figure 1, the LVEDVI decreased significantly in both groups after surgery (group A, from $170.1 \pm 36.0$ to $123.7 \pm 29.8 \mathrm{~mL} \cdot \mathrm{m}^{-2}$; group $\mathrm{B}$, from $126.6 \pm 26.3$ to $\left.95.1 \pm 14.8 \mathrm{~mL} \cdot \mathrm{m}^{-2} ; P<.0001\right)$. However, group A had a significantly greater LVEDVI than group B preoperatively and postoperatively $(P<.0001)$. The
TABLE 2. Surgical data

\begin{tabular}{lcccc}
\hline \multicolumn{1}{c}{ Parameter } & $\begin{array}{c}\text { Total } \\
(\mathbf{n}=\mathbf{5 0})\end{array}$ & $\begin{array}{c}\text { Group A } \\
(\mathbf{n}=\mathbf{1 7})\end{array}$ & $\begin{array}{c}\text { Group B } \\
(\mathbf{n}=\mathbf{3 3})\end{array}$ & $\begin{array}{c}\boldsymbol{P} \text { value } \\
\text { (A vs B) }\end{array}$ \\
\hline Region of MV prolapse & & & & .65 \\
$\quad$ Anterior & $14(28)$ & $4(24)$ & $10(30)$ & \\
$\quad$ Posterior & $25(50)$ & $8(47)$ & $17(52)$ & \\
$\quad$ Bileaflet & $11(22)$ & $5(29)$ & $6(18)$ & \\
MV repair & $36(72)$ & $12(71)$ & $24(73)$ & .87 \\
TAP & $22(44)$ & $11(65)$ & $11(33)$ & .03 \\
Maze procedure & $14(28)$ & $7(41)$ & $7(21)$ & .14 \\
CPB time (min) & $179 \pm 45$ & $195 \pm 49$ & $171 \pm 41$ & .08 \\
Aortic cross-clamp & $123 \pm 39$ & $135 \pm 48$ & $116 \pm 33$ & .11 \\
$\quad$ time (min) & & & & \\
\hline
\end{tabular}

Data presented as mean \pm SD or number (percentages). Group A, patients with LV dysfunction; group B, patients without $\mathrm{LV}$ dysfunction. $M V$, Mitral valve; $T A P$, tricuspid annuloplasty; $C P B$, cardiopulmonary bypass.

interaction of LVEDVI between the groups was not significant $(P=.17)$.

Although the LVESVI in group A decreased (from 75.1 \pm 14.0 to $65.4 \pm 27.3 \mathrm{~mL} \cdot \mathrm{m}^{-2}$ ), it increased slightly in group B (from $38.4 \pm 10.1$ to $40.7 \pm 9.5 \mathrm{~mL} \cdot \mathrm{m}^{-2}$ ). Group A had a significantly greater LVESVI than group B preoperatively and postoperatively $(P<.0001)$. The interaction of LVESVI between the groups was not significant $(P=.06)$.

Consequently, the LVEF deteriorated remarkably in both groups (group A, from $54.7 \% \pm 10.7 \%$ to $47.9 \% \pm$ $14.4 \%$; group $\mathrm{B}$, from $69.5 \% \pm 5.9 \%$ to $57.1 \% \pm 8.3 \%$; $P<.0001)$. Moreover, group B had a significantly greater LVEF than group A pre- and postoperatively $(P<.0001)$. The interaction of LVEF between the groups was not significant $(P=.16)$.

\section{Performance and LVM Regression Parameters}

As shown in Figure 2, the Ees did not change significantly $(P=.94)$ in either group A (from $1.2 \pm 0.2$ to 1.4 $\pm 0.6 \mathrm{~mm} \mathrm{Hg} \cdot \mathrm{m}^{2} \cdot \mathrm{mL}^{-1}$ ) or group B (from $2.4 \pm 0.8$ to $\left.2.1 \pm 0.5 \mathrm{~mm} \mathrm{Hg} \cdot \mathrm{m}^{2} \cdot \mathrm{mL}^{-1}\right)$. However, the difference in Ees between the groups was significant $(P<.0001)$. The interaction of Ees between the groups was not significant $(P=.08)$. The Ea increased dramatically and similarly in both groups after surgery (group A, from $1.4 \pm 0.6$ to 2.1 $\pm 0.7 \mathrm{~mm} \mathrm{Hg} \cdot \mathrm{m}^{2} \cdot \mathrm{mL}^{-1}$; group B, from $1.4 \pm 0.4$ to $2.2 \pm$ $\left.0.5 \mathrm{~mm} \mathrm{Hg} \cdot \mathrm{m}^{2} \cdot \mathrm{mL}^{-1} ; P<.0001\right)$. The interaction of Ea between the groups was not significant $(P=.63)$.

Consequently, Ea/Ees and SW/PVA deteriorated significantly after surgery (group A, from $1.3 \pm 0.8$ to $1.8 \pm 1.2$ and $63.6 \% \pm 11.1 \%$ to $56.5 \% \pm 13.5 \%$; group $\mathrm{B}$, from $0.6 \pm 0.2$ to $1.1 \pm 0.3$ and $76.6 \% \pm 4.8 \%$ to $65.7 \% \pm$ $6.8 \% ; P=.0004$ and $P<.0001$, respectively). Group B had significantly superior $\mathrm{Ea} / \mathrm{Ees}$ and SW/PVA before and after surgery compared with group A $(P<.0001$ and $P<.0001$, respectively). The interactions of $\mathrm{Ea} / \mathrm{Ees}$ and SW/PVA between the groups were not significant $(P=.83$ and $P=.29$, respectively). 
LVEDVI $\left(\mathbf{m L} \cdot \mathbf{m}^{-2}\right)$

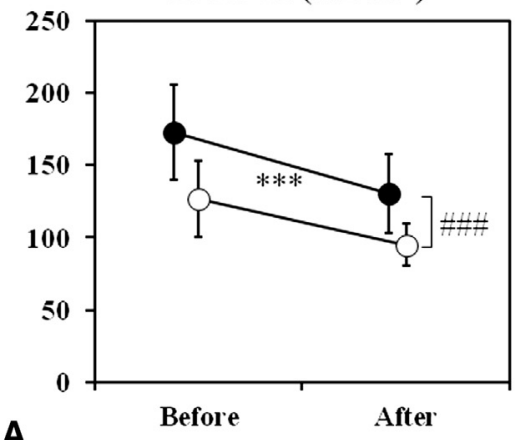

LVESVI $\left(\mathbf{m L} \cdot \mathbf{m}^{-2}\right)$

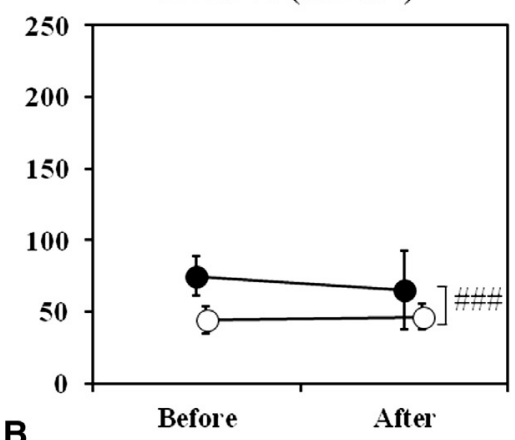

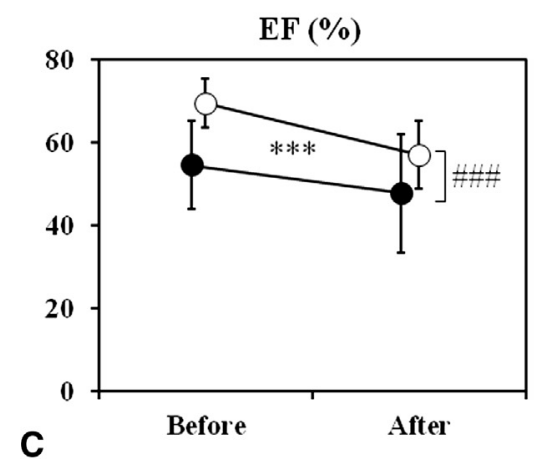

FIGURE 1. Changes in left ventricular $(L V)$ volume and ejection fraction $(E F)$ in the patients with (black circles, group A) and without (white circles, group B) LV dysfunction. LVEDVI, Left ventricular end-diastolic volume index; LVESVI, left ventricular end-systolic volume index. ***Before versus after surgery and \#\#\#group A versus B denote significant differences $(P<.001)$.

Finally, the LVMI decreased remarkably in both groups after surgery (group A, from 179.4 \pm 38.6 to $136.5 \pm 37.5 \mathrm{~g} \cdot \mathrm{m}^{-2}$; group B, from $153.0 \pm 40.5$ to $105.6 \pm 24.9 \mathrm{~g} \cdot \mathrm{m}^{-2} ; P<.0001$; Figure 3$)$. The difference in the LVMI between the groups was significant $(P=.0002)$, but the interaction was not $(P=.76)$.

\section{DISCUSSION}

The major findings from the present study were as follows: (1) LV contractility (Ees) remained unchanged, but the LV afterload (Ea) increased evenly; (2) LV efficiency (Ea/Ees and SW/PVA) deteriorated; (3) LVM reduced remarkably; and (4) early surgery preserved LV performance (greater contractility and less worsened efficiency) and improved LVM regression.

The effects of MR and subsequent MV surgery are not well understood because of the dramatic hemodynamic changes after surgery. A better understanding of the LV responses to changes in preload and afterload would help to clarify the mechanism of MR and its effect on the left ventricle. In the present study, we focused on the LV performance and LVM regression in the early postoperative phase. Suri and colleagues ${ }^{4}$ suggested that the early decrease in the LVEF after MV surgery is explainable by the compensatory alterations in LV volume and dimension rather than by postoperative LV dysfunction due to impaired myocardial contractility. Moreover, Ashikhmina and colleagues ${ }^{5}$ indicated that these changes are immediately noticeable after MV surgery for degenerative MR. Furthermore, they concluded that early LV remodeling after the surgery might be a compensatory mechanism to ensure a constant forward stroke volume. ${ }^{4,5}$ Our postoperative findings were similar to those of Suri and colleagues ${ }^{4}$; the patients had decreased LVEF and LVEDD but unchanged LVESD postoperatively, and the changes in LV dimension and LVEF in preserved LV function were superior to those with impaired LV function. Therefore, we believe that these findings were volumetric adjustments to maintain the forward stroke volume according to the preoperative LV function.

The LV performance parameters in the present study support this viewpoint. LV contractility remained unchanged, but LV afterload significantly increased after the surgery, irrespective of the LV functional status. Consequently, LV efficiency worsened. However, the patients with normal LV function had better LV contractility and efficiency than those with LV dysfunction. The effect of the deteriorated LV efficiency remains unknown. However, these findings show that early surgery should be recommended for patients with chronic severe MR and normal LV function.

Moreover, Starling ${ }^{22}$ reported that such patients with preserved LVEF have impaired LV contractility that is reversible 1 year after MV surgery. However, Starling ${ }^{22}$ also demonstrated that some patients with impaired LV contractility do not have improved contractile function and LV 

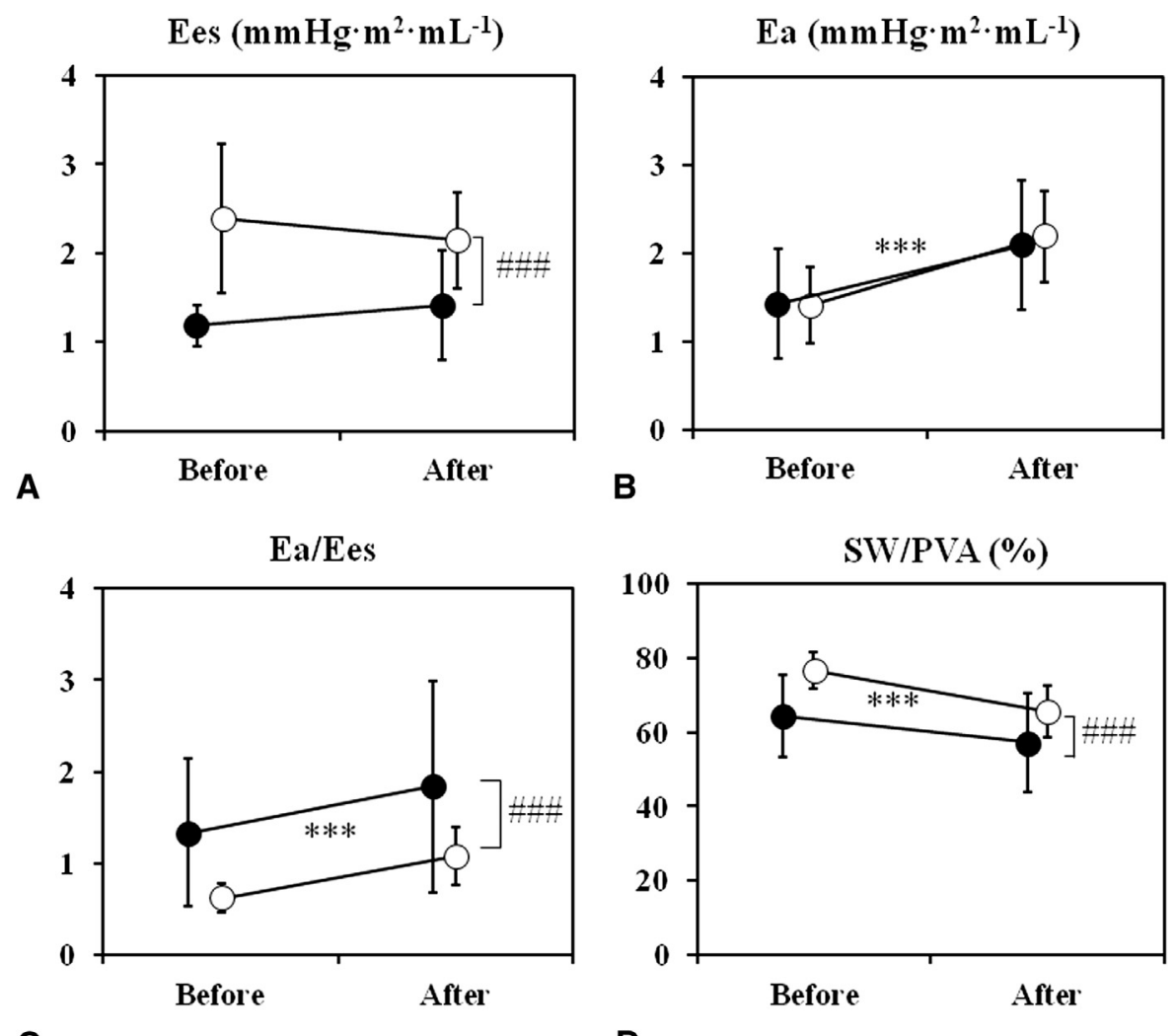

FIGURE 2. Changes in left ventricular ( $L V)$ performance in patients with (black circles, group A) and without (white circles, group B) LV dysfunction. Ees, End-systolic elastance; Ea, effective arterial elastance; Ea/Ees, ventriculoarterial coupling; SW/PVA, stroke work/pressure-volume area ratio. ***Before versus after surgery and \#\#\#group A versus B denote significant differences $(P<.001)$.

efficiency. Therefore, the indexes of LV contractility (Ees) and LV efficiency (Ea/Ees or SW/PVA) possibly predict the recovery of normal LV function.

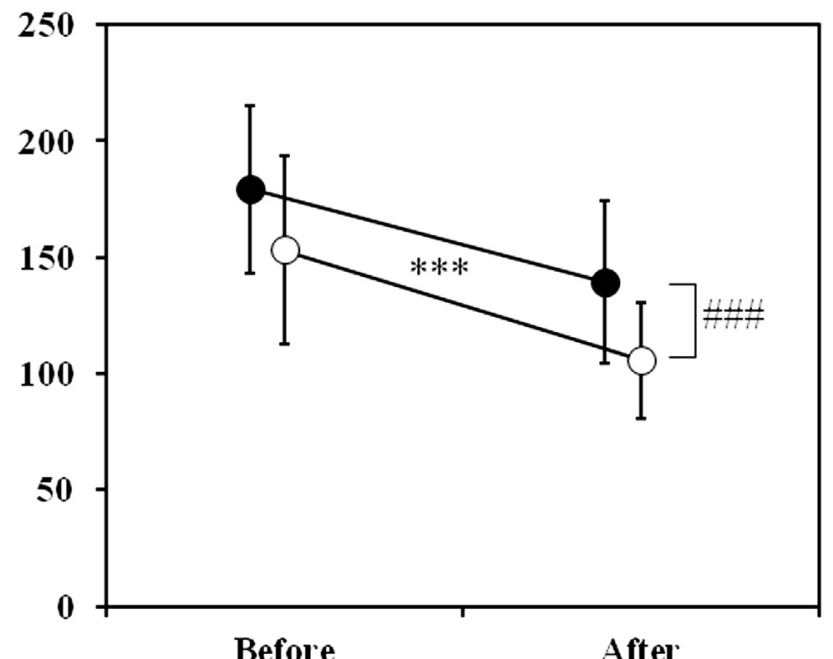

FIGURE 3. Changes in left ventricular mass index in patients with (black circles, group A) and without (white circles, group B) LV dysfunction. ***Before versus after surgery and \#\#\#group A versus B denote significant differences $(P<.001)$.
Stulak and colleagues ${ }^{17}$ reported that MV repair for leaflet prolapse performed before a decrease in the EF and development of significant secondary tricuspid regurgitation is associated with a greater likelihood of significant LVM regression after 3 years. In the present study, we found that the LVM had already regressed in the early postoperative phase. Moreover, the extent of regression was superior in the patients with normal LV function compared with those with LV dysfunction. Schuler and colleagues ${ }^{23}$ and Zile and colleagues ${ }^{24}$ observed that patients who achieved a normal LVEDD after MV replacement had a better functional result than those with persistent LV enlargement. In our study, the advantage of LVM regression in the patients with normal LV function was the associated superiority of the LV performance. At present, LV performance and LVM regression are not covered in the guidelines of MV surgery for severe MR. Despite the insufficient follow-up in our study, we believe that LV performance and LVM regression are important factors for early MV surgery.

\section{Study Limitations}

First, all data were obtained retrospectively by chart and database review, which has inherent limitations. Second, the Simpson method is more suitable than the Teichholz 
method for calculating the LV volume; however, only the LV diameter values were available in our study. Third, the approximation of Ees and Ea is not as accurate as measurements obtained using a conductance catheter system, and the volume intercept could not be measured. This approximation was validated using a canine right-heart bypass, which can draw the maximum capacity of a conductance catheter system. ${ }^{8,15}$ Furthermore, the validation was performed only on normal canine hearts, which differ from diseased human hearts. However, we believe that the limitations of such an approximation are consistent across groups and did not detract the validity of our conclusions. Fourth, the short follow-up period (1 month after surgery) is another limitation. The LVEF, LV dimension, and LVM after the MV surgery for chronic severe MR have been found to improve and lead to recovery of normal LV function over time. ${ }^{17,25}$ Studies evaluating the long-term effects of earlier surgery in terms of LV mechanics are therefore required. Finally, the New York Heart Association functional classification system has inherent limitations, which might have altered the inclusion and exclusion processes. Ideally, patients should be classified according to the results of an exercise test. Unfortunately, these data were unavailable for most of our patients.

\section{CONCLUSIONS}

LV efficiency in asymptomatic or minimally symptomatic patients with chronic severe MR deteriorates because of increased LV afterload at 1 month after MV surgery. However, treated patients with normal LV function benefit from the greater LV contractility, less worsened LV efficiency, and better LVM regression. Furthermore, LVM regression occurs immediately after surgery, and the extent of LVM regression in the case of normal LV function was superior to that in the case of LV dysfunction. These data support the view that early MV surgery for chronic severe MR optimizes LV performance and LVM regression during the early postoperative period ( 1 month after the surgery). However, long-term evaluations of LV performance and LVM regression are needed before any definitive conclusion can be drawn.

The present study was prepared in consultation with Professor Masahiro Nakano, PhD, Junshin Gakuen University, for statistical analyses.

\section{References}

1. Nkomo VT, Gardin JM, Skelton TN, Gottdierner JS, Scott CG, EnriquezSarano M. Burden of valvular heart disease: a population-based study. Lancet. 2006;368:1005-11

2. Rosenhek R, Rader F, Klaar U, Gabriel H, Krejc M, Kalbeck D, et al. Outcome of watchful waiting in asymptomatic severe mitral regurgitation. Circulation. 2006; 113:2238-44.

3. Bonow RO, Carabello BA, Chatterjee K, de Leon AC Jr, Faxon DP, Freed MD, et al. ACC/AHA 2006 guidelines for the management of patients with valvular heart disease: a report of the American College of Cardiology/American Heart
Association Task Force on Practice Guidelines (Writing Committee to revise the 1998 Guidelines for the Managements of Patients With Valvular Heart Disease). Circulation. 2006;114:e84-231.

4. Suri RM, Schaff HV, Dearani JA, Sundt TM III, Daly RC, Mullany CJ, et al. Determinants of early decline in ejection fraction after surgical correction of mitral regurgitation. J Thorac Cardiovasc Surg. 2008;136:442-7.

5. Ashikhmina EA, Schaff HV, Suri RM, Enriquez-Sarano M, Abel MD. Left ventricular remodeling early after correction of mitral regurgitation: maintenance of stroke volume with decreased systolic indexes. J Thorac Cardiovasc Surg. 2010; 140:1300-5.

6. Suga H. Ventricular energetics. Physiol Rev. 1990;70:247-77.

7. Burkhoff D, Sagawa K. Ventricular efficiency predicted by an analytical model. Am J Physiol. 1986;250:R1021-7.

8. Tanoue Y, Sese A, Ueno Y, Joh K, Hijii T. Bidirectional Glenn procedure improves the mechanical efficiency of a total cavopulmonary connection in high-risk Fontan candidates. Circulation. 2001;103:2176-80.

9. Tanoue Y, Sese A, Imoto Y, Joh K. Ventricular mechanics in the bidirectional Glenn procedure and total cavopulmonary connection. Ann Thorac Surg. 2003;76:562-6.

10. Tanoue Y, Kado H, Maeda T, Shiokawa Y, Fusazaki N, Ishikawa S. Left ventricular performance of pulmonary atresia with intact ventricular septum after right heart bypass surgery. J Thorac Cardiovasc Surg. 2004;128:710-7.

11. Tanoue Y, Kado H, Shiokawa Y, Fusazaki N, Ishikawa S. Midterm ventricular performance after Norwood procedure with right ventricular-pulmonary artery conduit. Ann Thorac Surg. 2004;78:1965-71.

12. Tanoue Y, Ando H, Fukumura F, Umesue M, Uchida T, Taniguchi K, et al. Ventricular energetics in endoventricular circular patch plasty for dyskinetic anterior left ventricular aneurysm. Ann Thorac Surg. 2003;75:1205-9.

13. Tanoue Y, Maeda T, Oda S, Baba H, Oishi Y, Tokunaga S, et al. Left ventricular performance in aortic valve replacement. Interact Cardiovasc Thorac Surg. 2009;9:255-9.

14. Tanoue Y, Tomita Y, Morita S, Tominaga R. Ventricular energetics in aortic root replacement for annuloaortic ectasia with aortic regurgitation. Heart Vessels. 2009;24:41-5.

15. Tanoue Y, Morita S, Hisahara M, Tominaga R, Kawachi Y, Yasui H. Influence of cyclic variation of right ventricular volume on left ventricular mechanical parameters measured with conductance catheter. Jpn Circ J. 2001;65:749-52.

16. Pellikka PA, Sarano ME, Nishimura RA, Malouf JF, Bailey KR, Scott CG, et al. Outcome of 622 adults with asymptomatic, hemodynamically significant aortic stenosis during prolonged follow-up. Circulation. 2005;111:3290-5.

17. Stulak JM, Suri RM, Dearani JA, Burkhart HM, Sundt TM III, EnriquezSarano M, et al. Does early surgical intervention improve left ventricular mass regression after mitral valve repair for leaflet prolapse? J Thorac Cardiovasc Surg. 2011;141:122-9.

18. Zoghbi WA, Enriquez-Sarano M, Foster E, Grayburn PA, Kraft CD, Levine RA, et al. Recommendations for evaluation of the severity of native valvular regurgitation with two-dimensional and Doppler echocardiography. J Am Soc Echocardiogr. 2003;16:777-802.

19. Teichholz LE, Kreulen T, Herman MV, Gorlin R. Problems in echocardiographic volume determinations: echocardiographic-angiographic correlations in the presence of absence of asynergy. Am J Cardiol. 1976;37:7-11.

20. Nozawa T, Yasumura Y, Futaki S, Tanaka N, Uenishi M, Suga H. Efficiency of energy transfer from pressure-volume area to external mechanical work increases with contractile state and decreases with afterload in the left ventricle of the anesthetized closed-chest dog. Circulation. 1988;77:1116-24.

21. Lang RM, Bierig M, Devereux RB, Flachskampf FA, Foster E, Pellikka PA, et al. Recommendations for chamber quantification: a report from the American Society of Echocardiography's Guidelines and Standards Committee and the Chamber Quantification Writing Group, developed in conjunction with the European Association of Echocardiography, a branch of the European Society of Cardiology. J Am Soc Echocardiogr. 2005;18:1440-63.

22. Starling MR. Effects of valve surgery on left ventricular contractile function in patients with long-term mitral regurgitation. Circulation. 1995;92:811-8.

23. Schuler G, Peterson KL, Johnson A, Francis G, Dennish G, Utley J, et al. Temporal response of left ventricular performance to mitral valve surgery. Circulation. 1979;59:1218-31.

24. Zile MR, Gaasch WH, Levine HJ. Left ventricular stress-dimension-shortening relations before and after correction of chronic aortic and mitral regurgitation. Am J Cardiol. 1985;56:99-105.

25. Suri RM, Schaff HV, Derani JA, Sundt TM, Daly RC, Mullany CJ, et al. Recovery of left ventricular function after surgical correction of mitral regurgitation caused by leaflet prolapse. J Thorac Cardiovasc Surg. 2009;137:1071-6. 